\title{
Electron Paramagnetic Resonance Examination of Free Radical Formation in Salicylic Acid and Urea Exposed to UV Irradiation
}

\author{
Pawel Ramos and Barbara Pilawa \\ School of Pharmacy with the Division of Laboratory Medicine, Medical University of Silesia in Katowice, \\ Department of Biophysics, Jedności 8, 41-200 Sosnowiec, Poland \\ Correspondence should be addressed to Paweł Ramos; pawelramos@sum.edu.pl
}

Received 23 October 2015; Revised 1 January 2016; Accepted 3 January 2016

Academic Editor: Maxim P. Evstigneev

Copyright (C) 2016 P. Ramos and B. Pilawa. This is an open access article distributed under the Creative Commons Attribution License, which permits unrestricted use, distribution, and reproduction in any medium, provided the original work is properly cited.

\begin{abstract}
Free radicals formed by UV irradiation of the two magistral formulas applied on the skin, salicylic acid and urea, were examined by X-band $(9.3 \mathrm{GHz})$ EPR spectroscopy. The influence of the time of UVA (315-400 nm) irradiation on free radical properties and concentrations in the drug samples was determined. The nonirradiated magistral formula did not contain free radicals. Amplitudes $(A)$ and linewidths $\left(\Delta B_{\mathrm{pp}}\right)$ of EPR spectra were analysed. Fast spin-lattice relaxation process existed in the tested drugs. UV irradiation did not change spin-lattice interactions in the tested magistral formula. Concentrations of free radicals formed by UV irradiation in salicylic acid and urea were $\sim 10^{17}-10^{18}$ spins/g. The strongest formation of free radicals under UV irradiation was observed for salicylic acid than for urea. Free radical concentration in salicylic acid increased with the increase of UV irradiation time from 15 minutes to 30 minutes, and after its value remained unchanged. The increase of free radical concentration in urea with UV irradiation time was stated. Salicylic acid is characterized with higher photosensitivity than urea. Salicylic acid, urea, and the skin treated by them should not be stored on UV exposure. The usefulness of EPR spectroscopy to optimize storage conditions of recipe drugs was conformed.
\end{abstract}

\section{Introduction}

Free radicals formed by UV irradiation in magistral formula, salicylic acid and urea, were examined.

Salicylic acid was applied in the formulation of pharmacy [1]. Salicylic acid is a well-established keratolytic and antiinflammatory [1-4]. Salicylic acid was used in concentrations of $0.5-60 \%$ in almost any base, including ointment, liquid, cream, or plaster, for the treatment of acne, psoriasis, warts, ichthyosis, and other hyperkeratotic disorders [1,2].

Urea was applied in the formulation of pharmacy $[1,5,6]$. Urea is used for proteolytic, keratolytic, hydrating, hygroscopic, penetration-enhancing, epidermis-thinning, and antipruritic effect $[1,6]$. Urea was used in concentrations of $10-40 \%$ in formulations like a base, ointment, cream, and liquid [4]. An increased water-binding capacity could be shown with water-in-oil emulsions containing $10 \%$ urea $[1,5,6]$. An increased hydration comparing $10 \%$ urea with $5 \%$ urea was not detectable in oil-in-water and water-in-oil emulsions $[1,5,6]$. This indicates that $5 \%$ urea is sufficient for a good hydration effect $[1,5,6]$.

Chemical structures of salicylic acid and urea were shown in Figures 1(a) and 1(b) [7], respectively.

Free radicals in drugs may be formed by thermal factor $[8,9]$ and UV irradiation $[10,11]$. The aim of this work was to check free radical formation by UV irradiation in salicylic acid and urea. Free radical problem was important for storage of these drugs as well as for their interaction in tissues.

\section{Experimental Method}

2.1. Samples. Nonirradiated and UV irradiated salicylic acid and urea samples were examined. The magistral formula was exposed to UVA irradiation with wavelengths $(\lambda)$ in the range of 315-400 nm during different times. The following times of irradiation, 15, 30, 45, and 60 minutes, were used. The UV irradiation was performed by the use of Medisun 250 lamp 
<smiles>O=C(O)c1ccccc1O</smiles>

(a)<smiles>NC(N)=O</smiles>

(b)

Figure 1: Chemical structure of (a) salicylic acid and (b) urea [7].

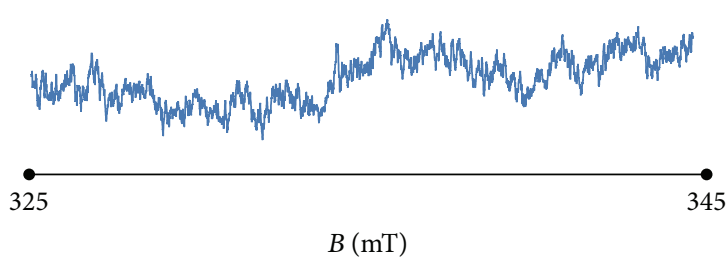

(a)

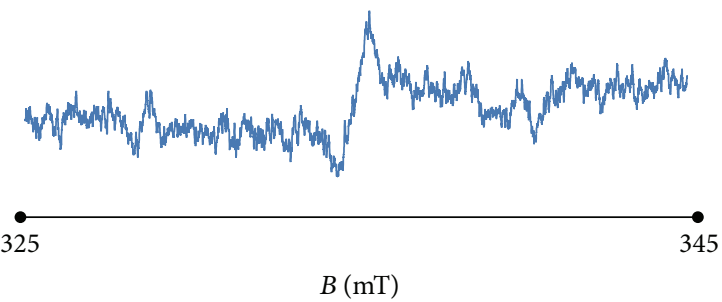

(b)

FIGURE 2: EPR spectra of (a) salicylic acid and (b) urea after UV irradiation for 60 minutes. Microwave power was $2.2 \mathrm{~mW}$. $B$ is the magnetic induction of the field produced by electromagnet of the EPR spectrometer.

(Germany) with 4 radiators with power of $20 \mathrm{~W}$. The distance of the samples from the lamp was $30 \mathrm{~cm}$.

2.2. EPR Measurements. For EPR measurements the magistral formula drugs were located in thin walled glass tubes without paramagnetic impurities. The external diameter of these tubes was $3 \mathrm{~mm}$. The mass of the samples in the tubes was determined by the use weight of Sartorius Firm (Germany).

Free radicals in the samples were examined by the X-band electron paramagnetic resonance spectrometer of Radiopan Firm (Poznań, Poland) with klystron produced microwaves of $9.3 \mathrm{GHz}$ frequency. Magnetic modulation was $100 \mathrm{kHz}$. Microwave frequency was measured by MCM101 recorder of EPRAD Firm (Poznań, Poland). EPR spectra were obtained by the system of numerical data acquisition, the Rapid Scan Unit of Jagmar Firm (Kraków, Poland) linked with the EPR spectrometer. The acquisition time of the individual EPR line was 1 second. The EPR spectra were measured in the range of microwave power of $2.2-70 \mathrm{~mW}$.

Amplitudes $(A)$ and linewidths $\left(\Delta B_{\mathrm{pp}}\right)$ of the EPR spectra were analysed. The effect of microwave power on the spectra was determined. $g$-factor was obtained as [12] $g=h \nu / \mu_{B} B_{r}$, where $h$ is Planck constant, $v$ is microwave frequency, $\mu_{B}$ is Bohr magneton, and $B_{r}$ is induction of resonance magnetic field.

Free radical concentrations $(N)$ in the UV irradiated drugs were determined by the use of ultramarine as the reference. The EPR spectra of the tested samples were compared with the resonance lines of ultramarine. The ruby crystal permanently placed in the resonance cavity was also used. To avoid microwave saturation effect the spectra of the samples and the references were measured with the low microwave power of $2.2 \mathrm{~mW}$. Free radical concentrations
(N) were calculated according to the formula $[12,13]$ : $N=N_{u}\left[\left(W_{u} A_{u}\right) / I_{u}\right] /[I /(W A m)]$, where $N_{u}$ is the number of paramagnetic centers in the reference, ultramarine; $W$, $W_{u}$ are the receiver gains for the tested samples and the ultramarine; $A, A_{u}$ are the amplitudes of ruby signal for the tested samples and the ultramarine; $I, I_{u}$ are the integral intensities for the tested samples and ultramarine; $m$ is the mass of the sample. The integral intensities $(I)$ of the EPR lines were obtained from double integration of the firstderivative curves.

The professional spectroscopic programs of Jagmar Firm (Kraków, Poland) and LabVIEW 8.5 of National Instruments Firm (Texas, USA) were used to measure and analyse the EPR spectra. The Origin of OriginLab Firm (USA) and Excel 2010 of Microsoft Firm (USA) programs were used.

\section{Results and Discussion}

EPR signals were not detected for nonirradiated salicylic acid and urea. Unpaired electrons were not in their chemical structure (Figure 1) [7]. The tested original drugs were diamagnetic and they did not absorb microwave in the magnetic field. The EPR spectra appeared after UV irradiation of these drugs independent of time of irradiation. The samples became paramagnetic and contained unpaired electrons. The EPR lines had the $g$ values near 2, which was characteristic for free radicals. The exemplary EPR spectra of salicylic acid and urea after UV irradiation during 60 minutes were presented in Figures 2(a) and 2(b), respectively. It was seen that the EPR signals were low, which corresponded in the low free radicals formation in the samples. The low contents of unpaired electrons resulted in the low absorption of microwaves by the samples located in the resonance cavity. The low values of 


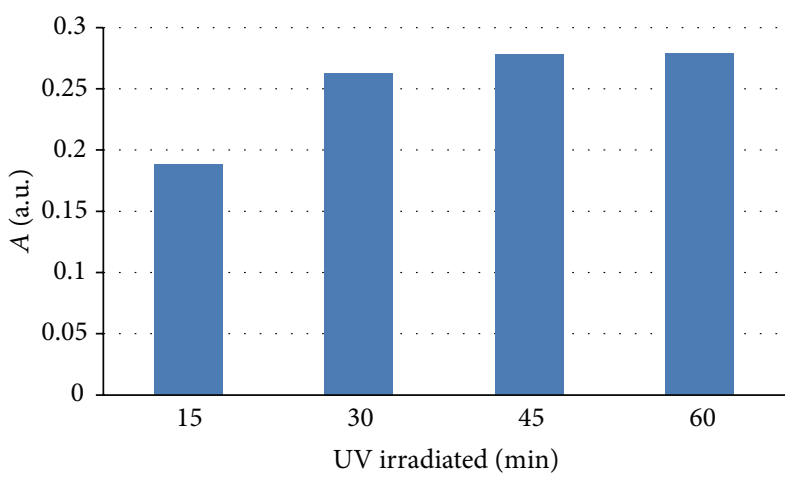

(a)

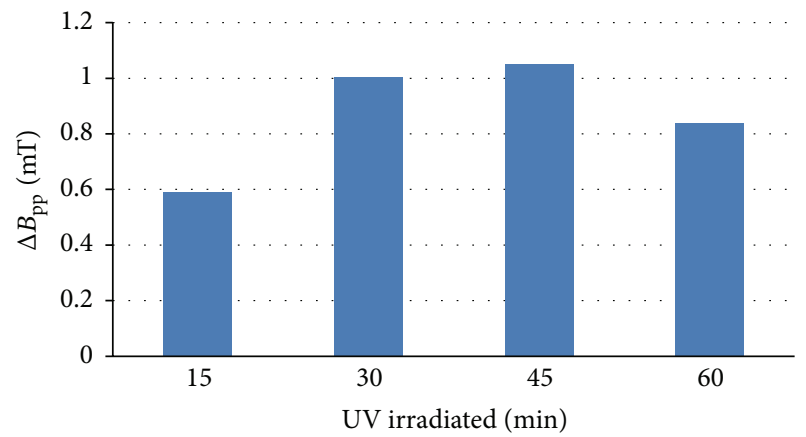

(b)

FIGURE 3: Comparison of (a) amplitudes $(A)$ and (b) linewidths $\left(\Delta B_{\mathrm{pp}}\right)$ of EPR spectra of salicylic acid after UV irradiation in different times.

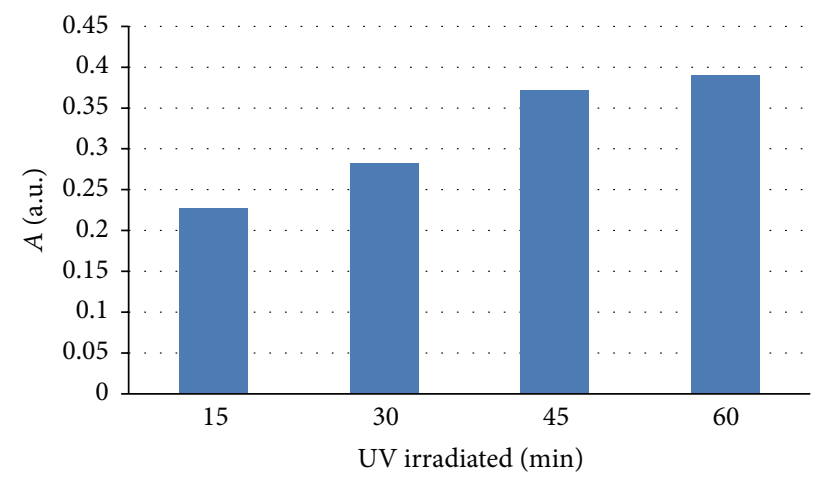

(a)

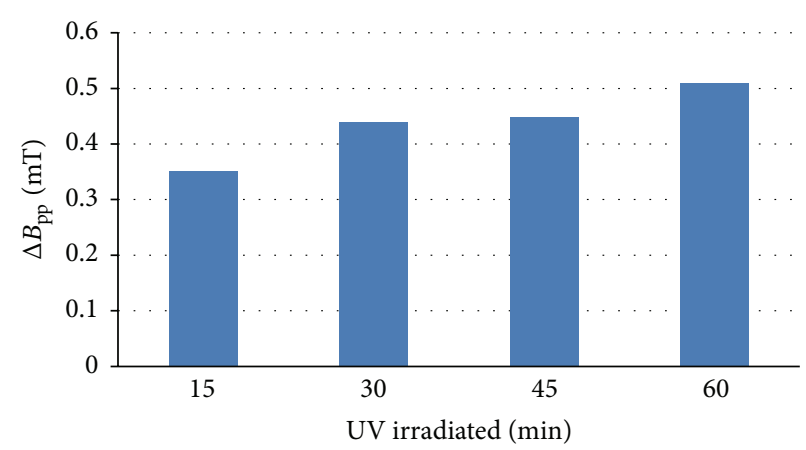

(b)

FIGURE 4: Comparison of (a) amplitudes $(A)$ and (b) linewidths $\left(\Delta B_{\mathrm{pp}}\right)$ of EPR spectra of urea after UV irradiation in different times.

amplitudes $(A)$, the basic parameters of the EPR spectra, were obtained.

The parameters of the EPR spectra of salicylic acid and urea after UV irradiation during different times were compared in Figures 3(a), 3(b), 4(a), and 4(b), respectively. In Figures 3(a) and 4(a) amplitudes $(A)$ were shown, and in Figures 3(b) and 4(b) linewidths $\left(\Delta B_{\mathrm{pp}}\right)$ were presented, for the UV irradiated samples by $15,30,45$, and $60 \mathrm{~min}$ utes. Amplitudes $(A)$ (Figure 3(a)) and linewidths $\left(\Delta B_{\mathrm{pp}}\right)$ (Figure 3(b)) of EPR spectra of UV irradiated salicylic acid sharply increased for the sample irradiated during 30 minutes relative to the sample irradiated during 15 minutes. Only the weak changes of amplitudes $(A)$ (Figure $3(\mathrm{a})$ ) and linewidths $\left(\Delta B_{\mathrm{pp}}\right)$ (Figure 3(b)) were observed with increasing the time of UV irradiation of salicylic acid. The results in Figures $3(\mathrm{a})$ and 3(b) indicated that UV irradiation caused changes in free radicals in salicylic acid during the first phase of irradiation (up to 15 minutes) and after the free radical effects were stabilized. However the changes in free radical system in urea existed during the whole time of UV irradiation. Amplitudes $(A)$ and linewidths $\left(\Delta B_{\mathrm{pp}}\right)$ of EPR spectra of urea increased with increasing of UV irradiation time (Figures 4(a) and 4(b)). The increase of amplitudes (A) (Figure 4(a)) corresponded to the increase of the amount of free radicals in the samples. The distances between free radicals decreased, then, as a result their dipolar interactions increased, and the lines broadened.

The parameters of the EPR spectra of the tested drugs depended on microwave power. The changes of amplitudes $(A)$ of EPR spectra of salicylic acid and urea with microwave power $\left(M / M_{o}\right)$ for the UV irradiated samples during 15 minutes, 30 minutes, 45 minutes, and 60 minutes were shown in Figures 5(a)-5(d) and 6(a)-6(d), respectively. The changes of linewidths $\left(\Delta B_{\mathrm{pp}}\right)$ of EPR spectra of salicylic acid and urea with microwave power $\left(M / M_{o}\right)$ for the UV irradiated samples during 15 minutes, 30 minutes, 45 minutes, and 60 minutes were shown in Figures $7(\mathrm{a})-7(\mathrm{~d})$ and $8(\mathrm{a})-$ 8(d), respectively. Amplitudes $(A)$ of all the measured EPR lines increased with increasing of microwave power (Figures 5 and 6). The EPR lines were not saturated in the used range of microwave power (up to $70 \mathrm{~mW}$ ). Such correlations were characteristic for the fast spin-lattice relaxation in the samples. After microwave excitation unpaired electrons fast returned to the lower energy levels. The inversion of location of unpaired electrons did not appear in the used range of microwave power. Linewidths $\left(\Delta B_{\mathrm{pp}}\right)$ of EPR lines of UV irradiated salicylic acid and urea increased with increasing of microwave power (Figures 7 and 8). The increase of EPR 


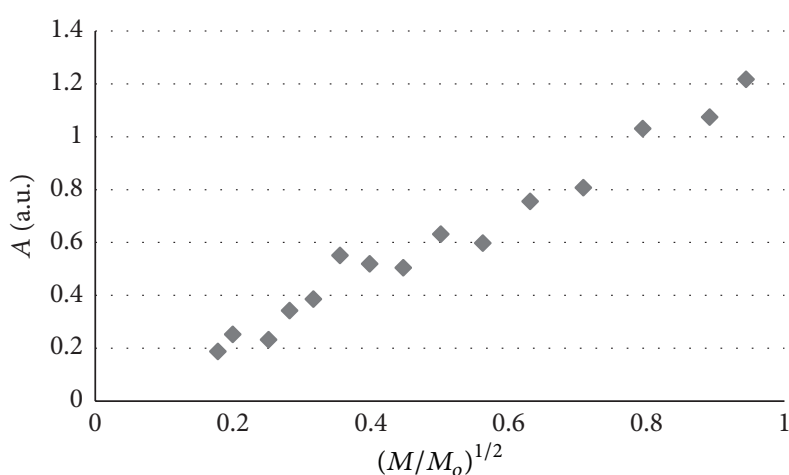

(a)

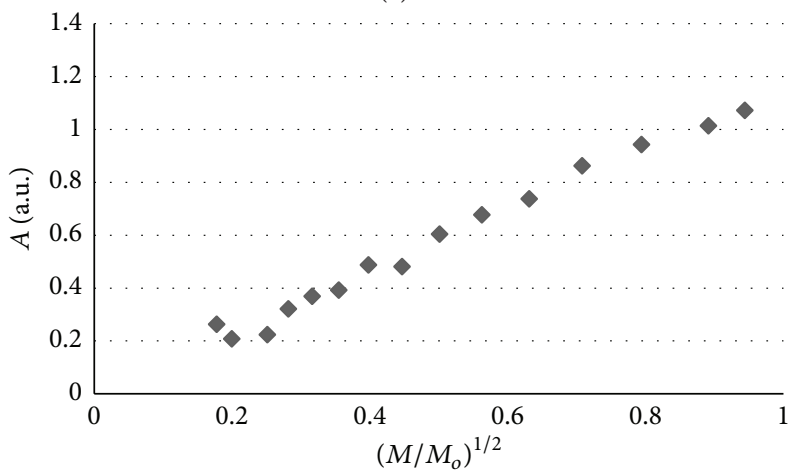

(c)

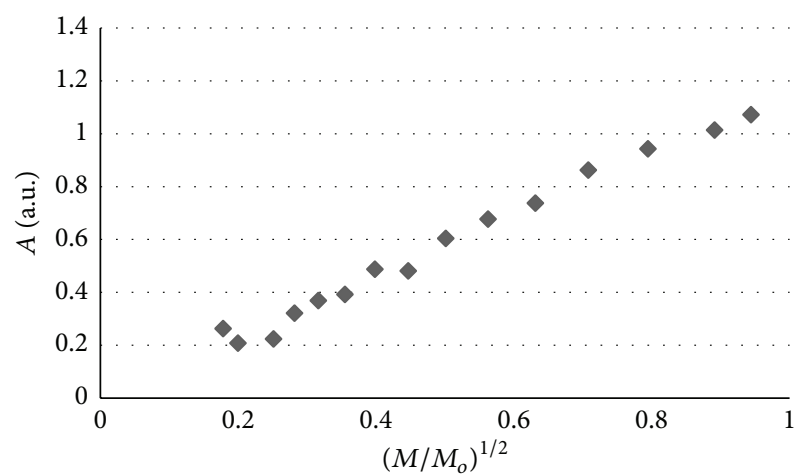

(b)

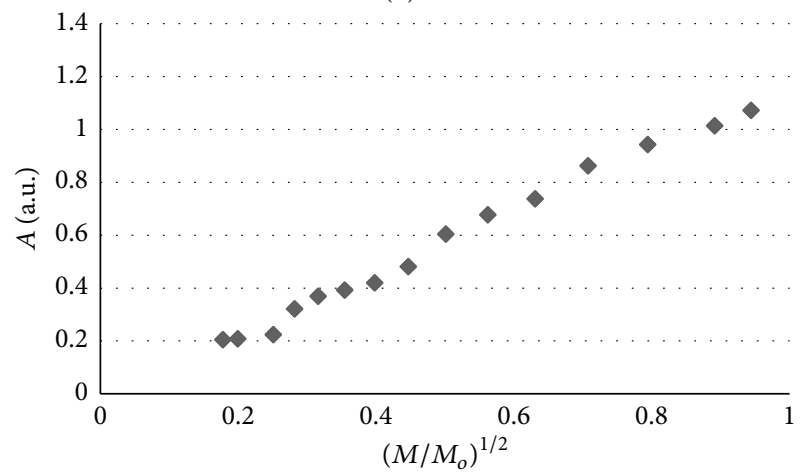

(d)

FIGURE 5: The effect of microwave power $\left(M / M_{o}\right)$ on amplitudes $(A)$ of the EPR spectra of UV irradiated salicylic acid during (a) 15 minutes, (b) 30 minutes, (c) 45 minutes, and (d) 60 minutes. $M$ : microwave power used during the measurement and $M_{o}$ : total microwave power produced by klystron $(70 \mathrm{~mW})$.

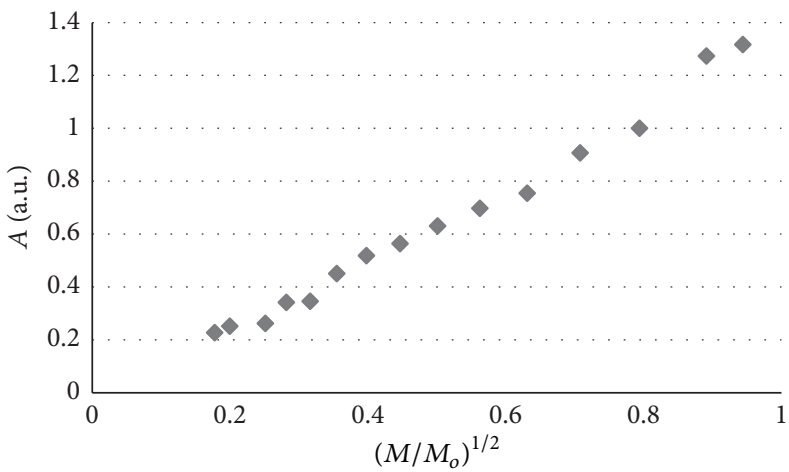

(a)

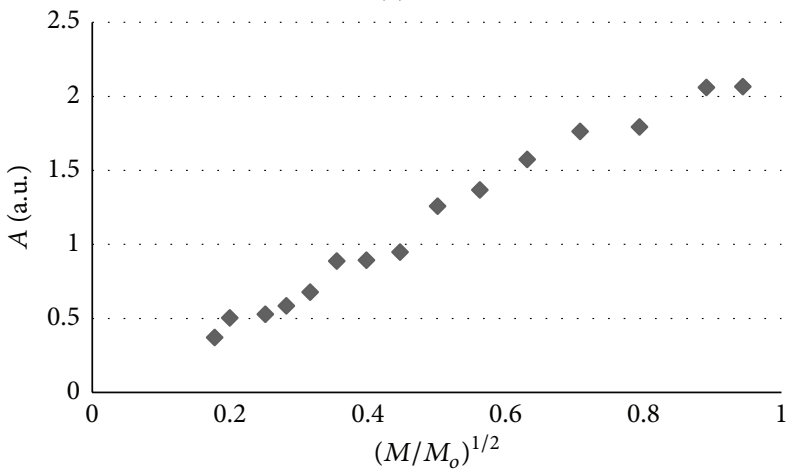

(c)

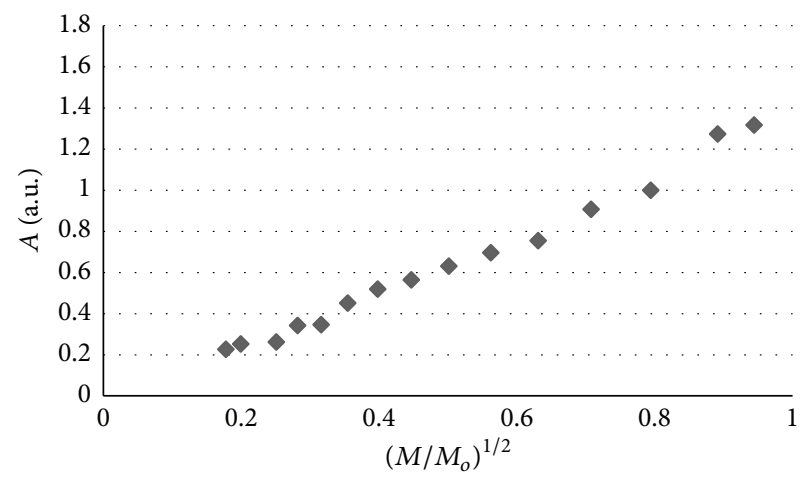

(b)

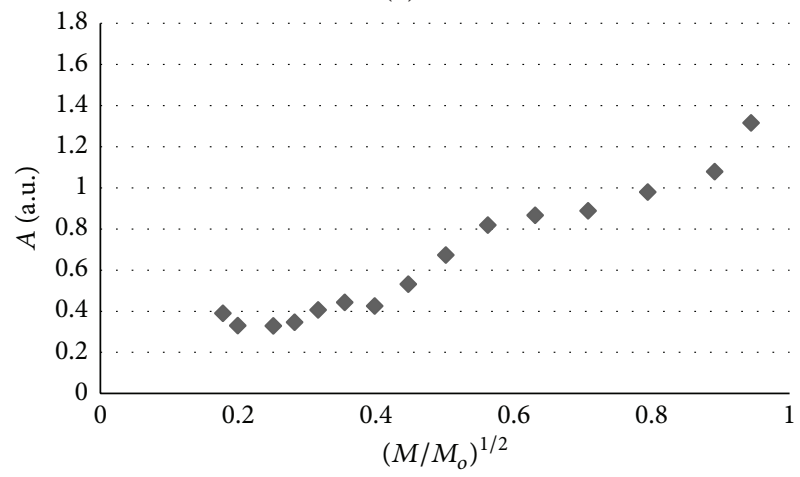

(d)

FIGURE 6: The effect of microwave power $\left(M / M_{o}\right)$ on amplitudes $(A)$ of the EPR spectra of UV irradiated urea during (a) 15 minutes, (b) 30 minutes, (c) 45 minutes, and (d) 60 minutes. $M$ : microwave power used during the measurement and $M_{o}$ : total microwave power produced by klystron $(70 \mathrm{~mW})$. 


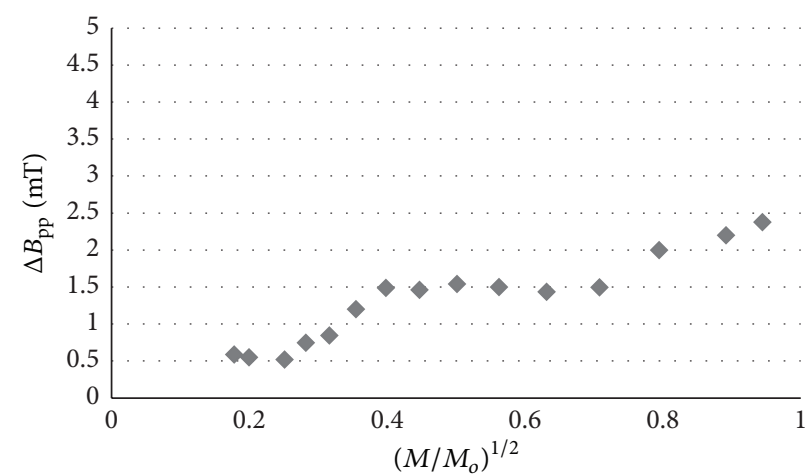

(a)

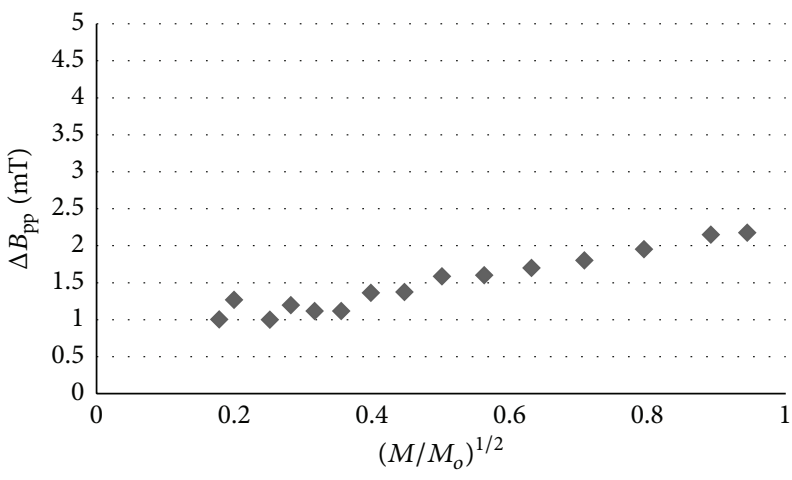

(c)

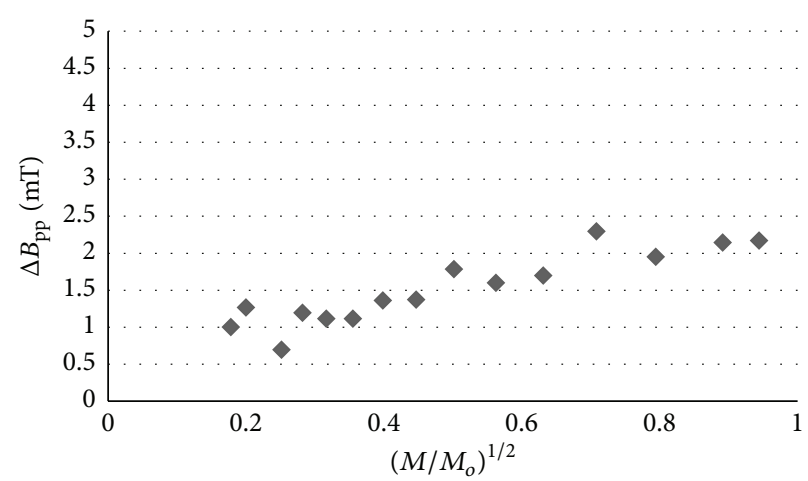

(b)

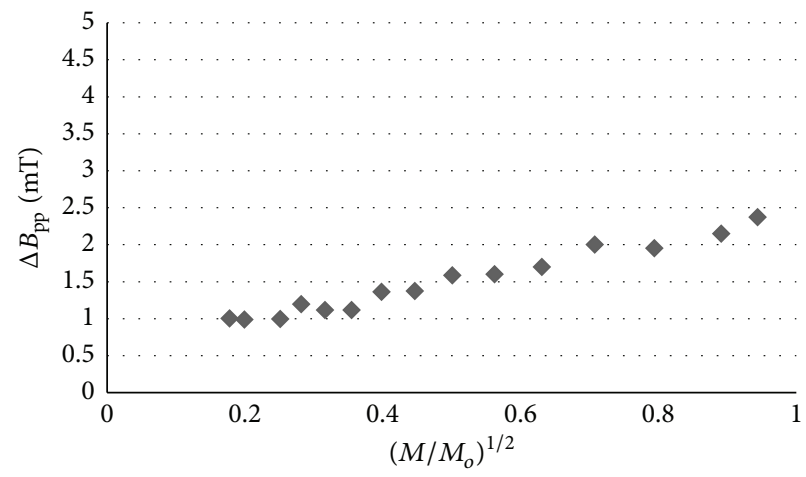

(d)

FIGURE 7: The effect of microwave power $\left(M / M_{o}\right)$ on linewidths $\left(\Delta B_{\mathrm{pp}}\right)$ of the EPR spectra of UV irradiated salicylic acid during (a) 15 minutes, (b) 30 minutes, (c) 45 minutes, and (d) 60 minutes. $M$ : microwave power used during the measurement and $M_{o}$ : total microwave power produced by klystron $(70 \mathrm{~mW})$.

spectra with increase of microwave power was characteristic for homogeneous broadened lines [12]. The homogeneous broadened EPR lines were also found by us earlier for UV irradiated dehydrocholic acid [10] and ursodeoxycholic acid [10].

The influence of UV irradiation time on free radical concentrations $(N)$ in salicylic acid and urea was presented in Figures 9(a) and 9(b), respectively. Free radical concentration in UV irradiated salicylic acid was $\sim 10^{18}$ spins/g (Figure 9(a)). The sharp increase of free radical concentration $(N)$ was observed for the salicylic acid sample irradiated during 30 minutes relative to the sample irradiated during 15 minutes. The prolongation of UV irradiation time to 45 and 60 minutes did not increase the free radical concentration in salicylic acid. The free radical effects were not developed during time after 30 minutes of irradiation. The other correlation was observed in urea (Figure 9(b)). Free radical concentration increased with time of UV irradiation of urea. The formation of free radicals in urea was observed during the whole time of UV irradiation. The free radical concentration $(N)$ in UV irradiated salicylic acid (Figure 9(a)) was higher than in urea (Figure 9(b)). The formation of free radicals under UV irradiation (Figure 9) indicated that salicylic acid and urea should be stored in the dark. The therapy by salicylic acid and urea exposed to UV irradiation may be accompanied by free radical reactions. Free radicals as the active molecules with unpaired electrons may be responsible for destruction of the skin and tissues $[14,15]$.

Application of electron paramagnetic resonance (EPR) spectroscopy is recommended for test of the photosensitivity of the drug samples on UV irradiation. This method directly brings to light information about concentration and properties of free radicals in the samples [12-14]. The important information about storage conditions of drugs may be obtained.

\section{Conclusions}

Electron paramagnetic resonance studies of the UV irradiated magistral formula pointed out the following conclusions:

(1) UV irradiation formed free radicals $\left(\sim 10^{18}\right.$ spins/g) in salicylic acid and urea, which revealed EPR spectra. The stronger photosensitivity and the higher free radical effect were observed for salicylic acid than for urea. The free radical concentration in UV irradiated salicylic acid $\left(5 \times 10^{18}\right.$ spins/g) was higher than in urea $\left(2.6 \times 10^{18} \mathrm{spins} / \mathrm{g}\right)$.

(2) Free radical formation in urea increased with increasing of UV irradiation time, while free radical concentration in salicylic acid stabilized after 30 minutes of UV irradiation. 


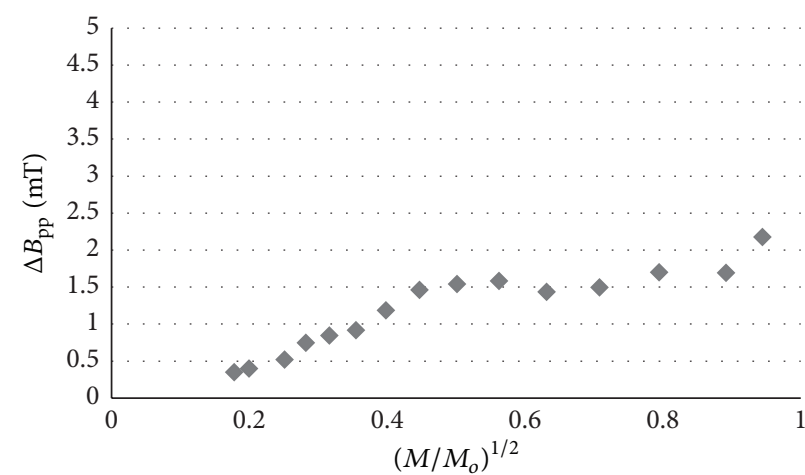

(a)

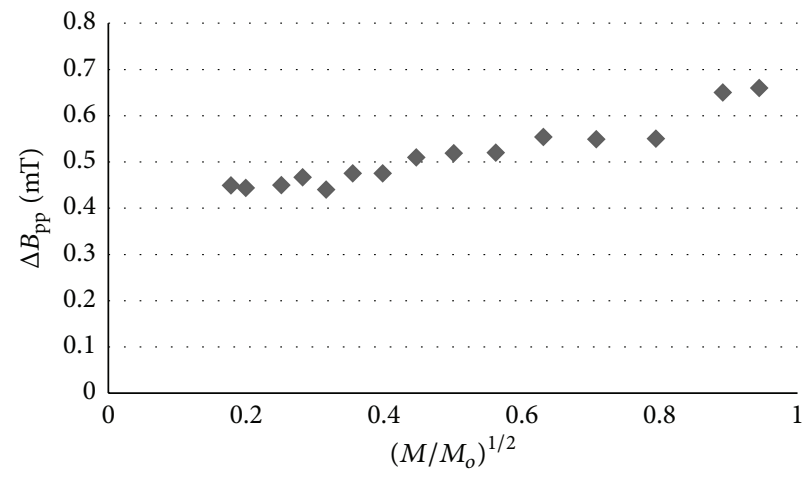

(c)

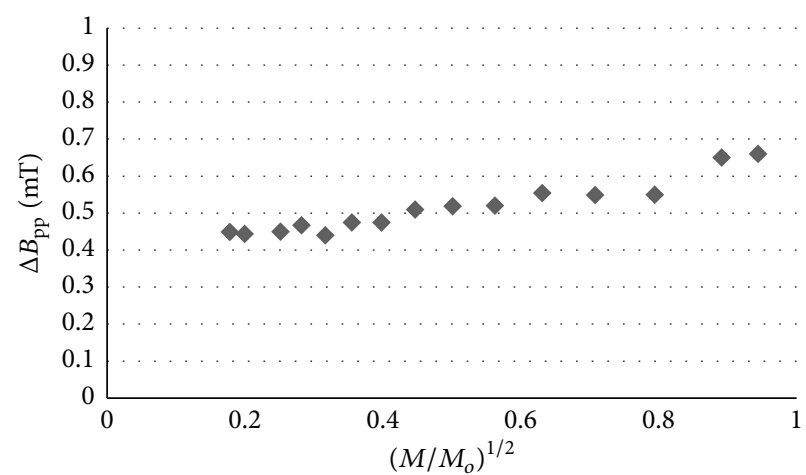

(b)

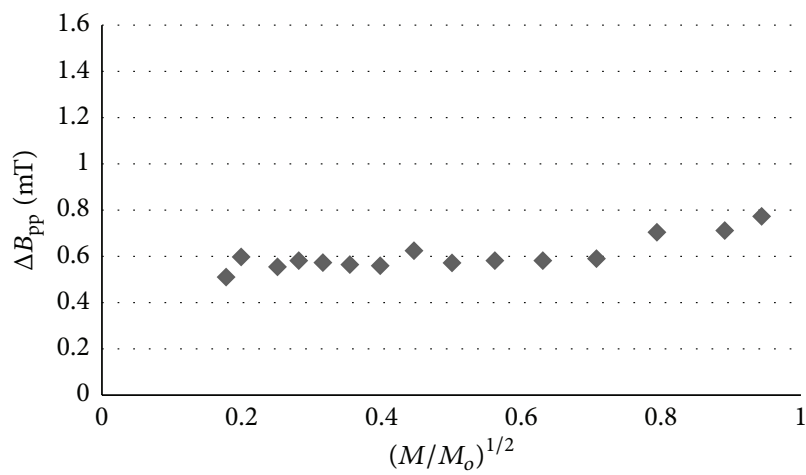

(d)

FIgURE 8: The effect of microwave power $\left(M / M_{o}\right)$ linewidths $\left(\Delta B_{\mathrm{pp}}\right)$ of the EPR spectra of UV irradiated urea during (a) 15 minutes, (b) 30 minutes, (c) 45 minutes, and (d) 60 minutes. $M$ : microwave power used during the measurement and $M_{o}$ : total microwave power produced by klystron $(70 \mathrm{~mW})$.

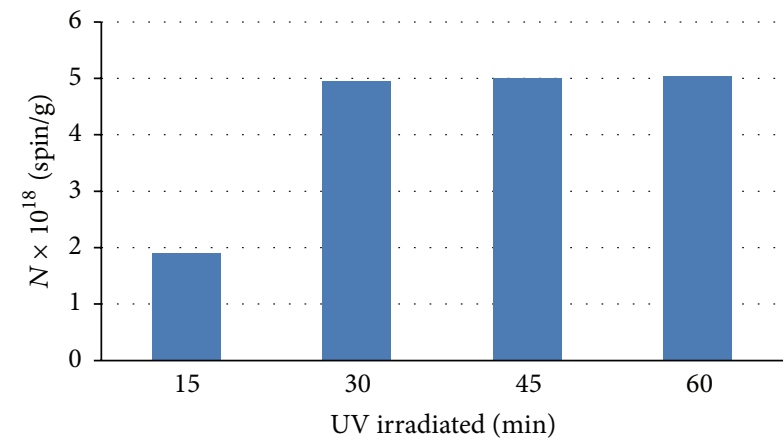

(a)

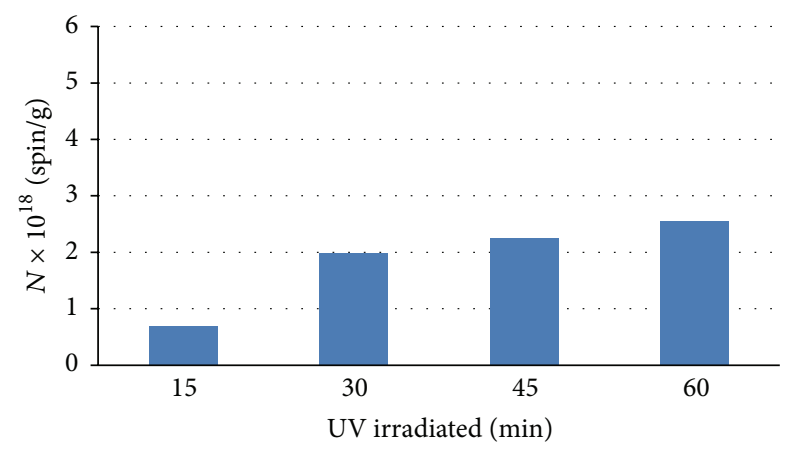

(b)

FIGURE 9: Comparison of free radical concentrations $(N)$ in (a) salicylic acid and (b) urea, after UV irradiation in different times.

(3) Fast spin-lattice relaxation existed in UV irradiated salicylic acid and urea.

(4) Free radicals formed by UV irradiation may interact with skin during therapy.

(5) Because of free radicals production via photolysis salicylic acid and urea should not be stored under UV irradiation.

\section{Conflict of Interests}

The authors declare that there is no conflict of interests regarding the publication of this paper. They have no conflict of interests or no financial gains in mentioning the company names or trademarks. As the authors of the paper, they do not have any financial relation with the commercial identity mentioned in their paper. 


\section{Acknowledgment}

This study was financially supported by Medical University of Silesia in Katowice, Grant no. KNW-2-007/N/5/K.

\section{References}

[1] R. Jachowicz, Recipe Pharmacy, PZWL, Warsaw, Poland, 2008 (Polish).

[2] S. J. Bashir, F. Dreher, A. L. Chew et al., "Cutaneous bioassay of salicylic acid as a keratolytic," International Journal of Pharmaceutics, vol. 292, no. 1-2, pp. 187-194, 2005.

[3] J.-C. Tsai, S.-A. Chuang, M.-Y. Hsu, and H.-M. Sheu, "Distribution of salicylic acid in human stratum corneum following topical application in vivo: a comparison of six different formulations," International Journal of Pharmaceutics, vol. 188, no. 2, pp. 145-153, 1999.

[4] A. Jabarah, L. T. Gilead, and A. Zlotogorski, "Salicylate intoxication from topically applied salicylic acid," Journal of the European Academy of Dermatology and Venereology, vol. 8, no. 1, pp. 41-42, 1997.

[5] J. W. Fluhr, C. Cavallotti, and E. Berardesca, "Emollients, moisturizers, and keratolytic agents in psoriasis," Clinics in Dermatology, vol. 26, no. 4, pp. 380-386, 2008.

[6] L. C. Parish and J. A. Witkowski, "Traditional therapeutic agents," Clinics in Dermatology, vol. 18, no. 1, pp. 5-9, 2000.

[7] A. Zejca, Chemia Leków, PZWL, Warsaw, Poland, 2004 (Polish).

[8] P. Ramos and B. Pilawa, "Electron paramagnetic resonance study of thermally treated bismuth subgallate," Bioinorganic Chemistry and Applications, vol. 2014, Article ID 547032, 9 pages, 2014.

[9] P. Ramos and B. Pilawa, "Free radicals in thermally sterilized Acidum boricum and optimization of this process," Acta Poloniae Pharmaceutica: Drug Research, vol. 72, no. 4, pp. 683-689, 2015.

[10] M. Dołowy, P. Ramos, and B. Pilawa, "Effect of UV irradiation and temperature on free radical properties in dehydrocholic and ursodeoxycholic acids: an EPR study," International Journal of Photoenergy, vol. 2014, Article ID 953619, 7 pages, 2014.

[11] M. Skoumal, R. M. Rodríguez, P. L. Cabot et al., "ElectroFenton, UVA photoelectro-Fenton and solar photoelectroFenton degradation of the drug ibuprofen in acid aqueous medium using platinum and boron-doped diamond anodes," Electrochimica Acta, vol. 54, no. 7, pp. 2077-2085, 2009.

[12] J. E. Wertz and J. R. Bolton, Electron Spin Resonance: Elementary Theory and Practical Application, Chapman \& Hall, New York, NY, USA, 1986.

[13] J. Stankowski and W. Hilczer, Introduction to Magnetic Resonance Spectroscopy, Scientific Publishing, Warsaw, Poland, 2005.

[14] G. Bartosz, Druga Twarz Tlenu. Wolne Rodniki w Przyrodzie, PWN, Warsaw, Poland, 2015 (Polish).

[15] B. A. Jurkiewicz, D. L. Bissett, and G. R. Buettner, "Effect of topically applied tocopherol on ultraviolet radiation-mediated free radical damage in skin," Journal of Investigative Dermatology, vol. 104, no. 4, pp. 484-488, 1995. 

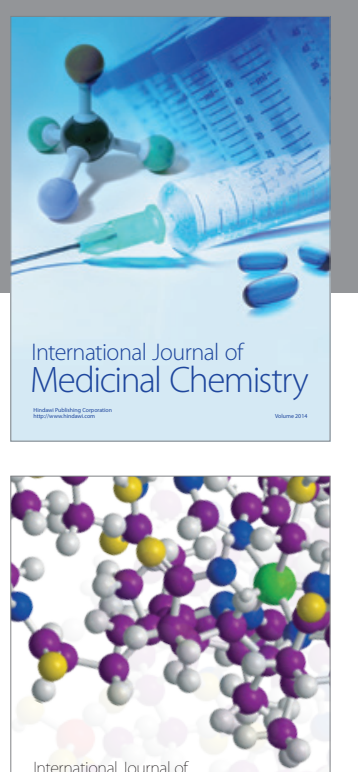

Carbohydrate Chemistry

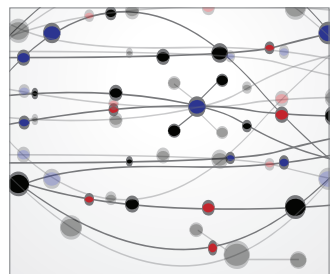

The Scientific World Journal
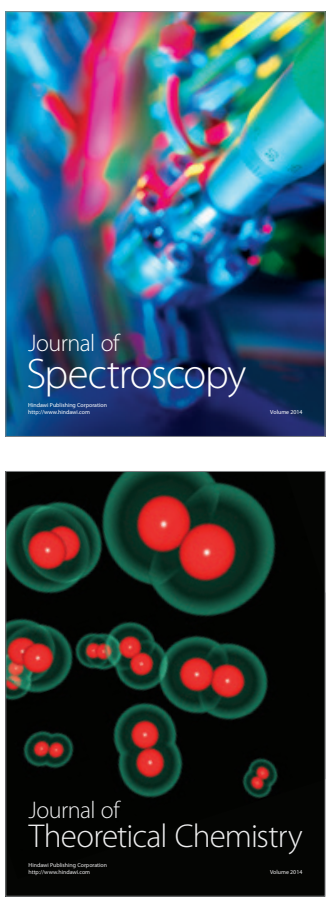
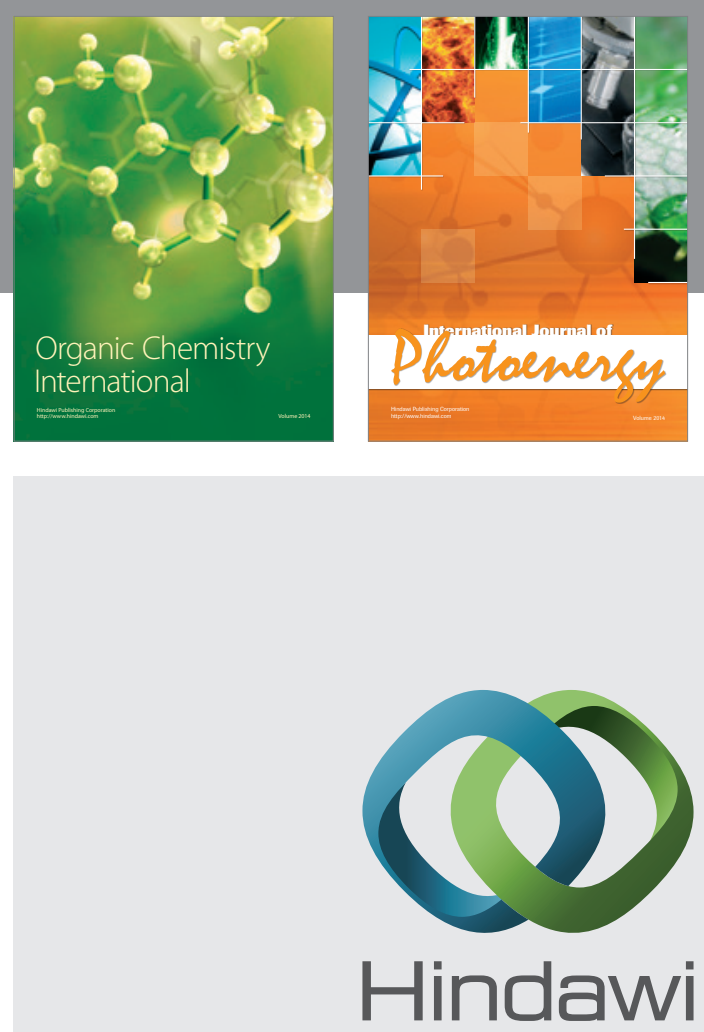

Submit your manuscripts at

http://www.hindawi.com

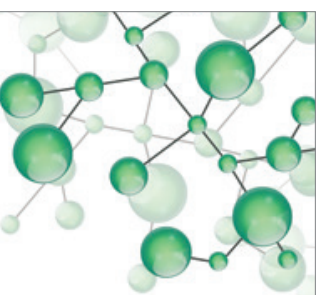

International Journal of

Inorganic Chemistry

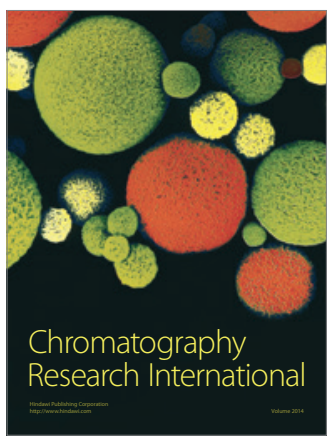

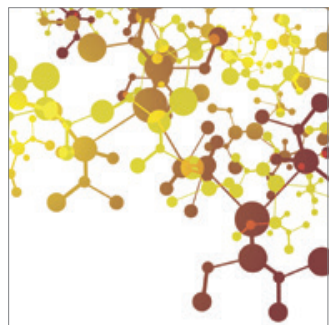

Applied Chemistry
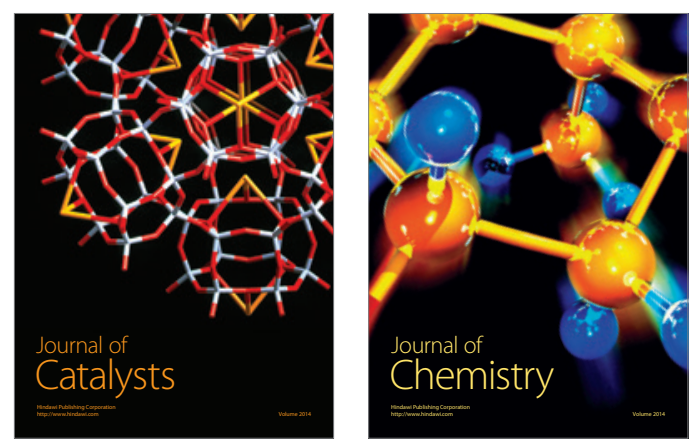
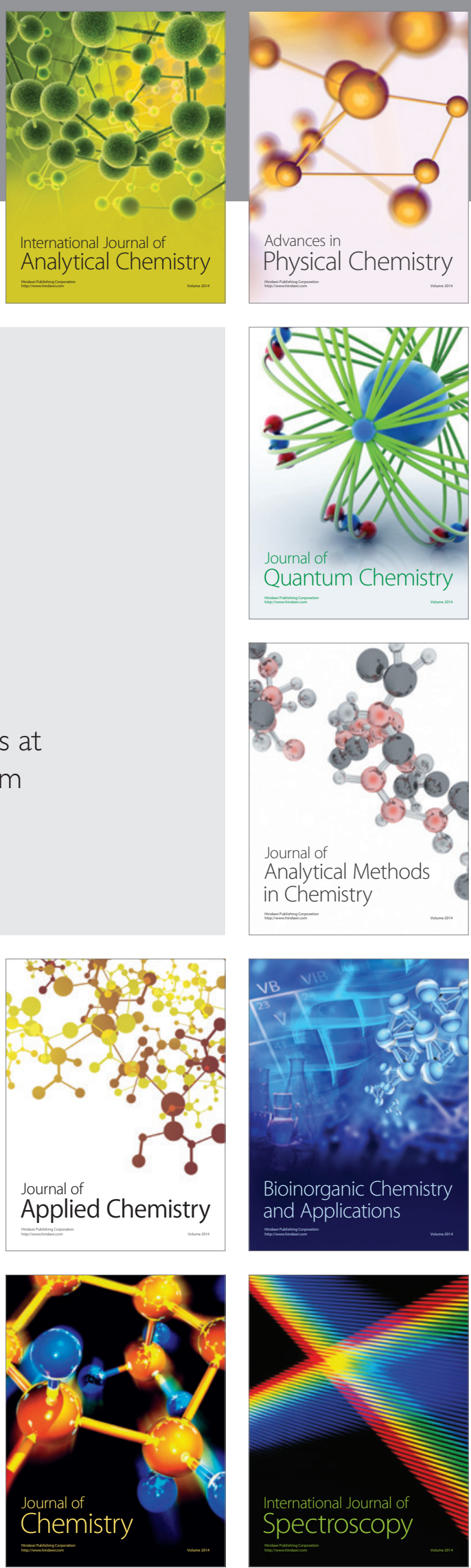